\title{
EFFECT OF HEAT TREATMENT AND COMPOSITIONAL MODIFICATION ON STRENGTH AND THERMAL STABILITY OF ALLOY 718
}

\author{
Encai Guo, Fengqin Xu and E.A. Loria \\ Central Iron \& Steel Research Institute \\ Beijing, China \\ and \\ Niobium Products Company \\ Pittsburgh, Pennsylvania, U.S.A.
}

\begin{abstract}
The strength of Alloy 718 must be improved beyond $650^{\circ} \mathrm{C}$ in order to meet the design needs for advanced aeroengines. A recent series of papers show particular promise via minor compositional modifications. Two modified 718 alloys that do so utilizing the standard 718 heat treatment were given heat treatments that changed the morphology of the coexisting $\gamma^{\prime} / \gamma^{\prime \prime}$ precipitates as a possible way of producing an additional improvement in mechanical properties. Tensile test results at room temperature and stress rupture life at $700^{\circ} \mathrm{C}$ and $638 \mathrm{MPa}(92.5 \mathrm{ksi})$ are presented which led to the selection of a heat treatment which provided superior properties in each case for the sequel study.
\end{abstract}

\section{Introduction}

The recent series of papers ${ }^{1-5}$ modifying the chemical composition of Alloy 718 has shown that mechanical properties beyond $650^{\circ} \mathrm{C}$ can be improved with either the non-compact or the compact $\gamma^{\prime} / \gamma^{\prime \prime}$ precipitate morphology obtained by appropriate heat treatment. The former is the conventional mixture of diskshaped $\gamma^{\prime \prime}$ and round $\gamma^{\prime}$ particles plus $\gamma^{\prime \prime}$ bound to $\gamma^{\prime}$ particles, thereby forming, to some degree, a hemispherical shape. The latter consists entirely of cuboidshaped $\gamma^{\prime}$ particles coated with a shell of $\gamma^{\prime \prime}$ particles. In our initial study employing the standard 718 heat treatment, ${ }^{1}$ which produced the conventional precipitate structure, four of our modified alloys produced superior hardness and tensile properties up to $534 \mathrm{hr}$ at $730^{\circ} \mathrm{C}$ plus the improvement in $100 \mathrm{hr}$ stress rupture life shown in Figure 1. Microstructurally, a slower rate of $\gamma$ " coarsening along with a larger $\gamma^{\prime}$ size and smaller $\gamma^{\prime \prime}$ length was observed which could mean that more $\gamma^{\prime}$ was produced while stabilizing the $\gamma^{\prime \prime}$ phase at the same time.

With the existence of both the $\gamma^{\prime}$ and $\gamma^{\prime \prime}$ phases in Alloy 718, it is tempting to consider heat treatments for a modified composition that would produce a greater amount of $\gamma^{\prime}$ phase in order to increase high temperature strength (in particular creep resistance). In contrast to the bct crystal structure of the $\gamma^{\prime \prime}$ phase, the much 


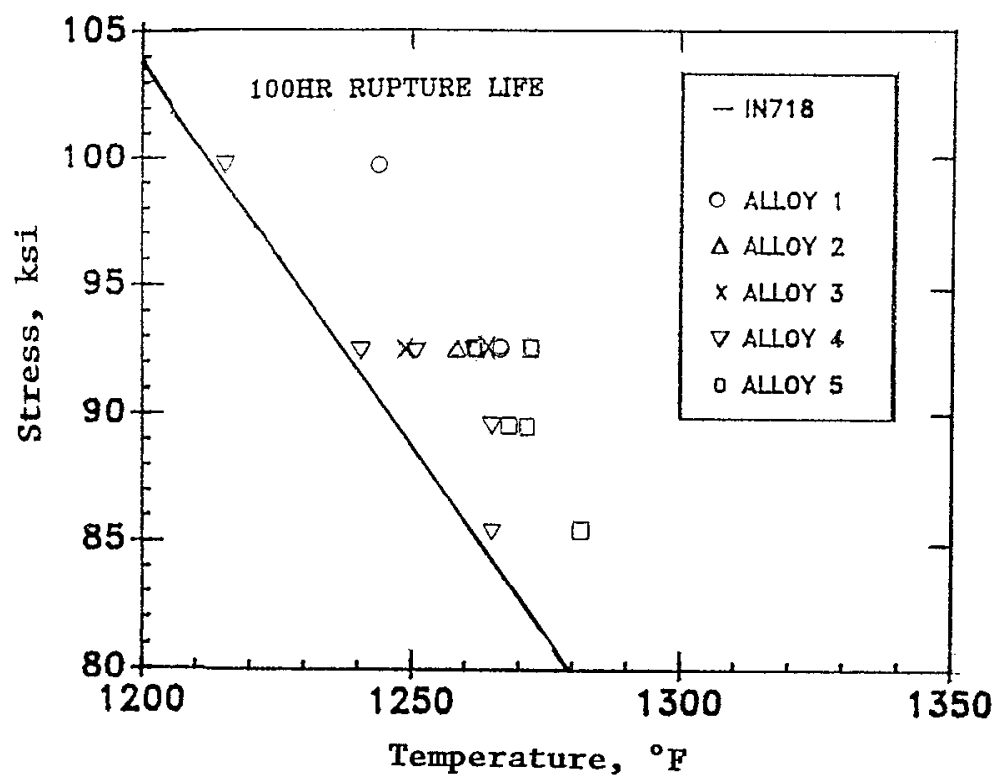

Figure 1-Conversion of stress rupture data for Alloys 1 to 5 to 100 hour rupture life via the Larson-Miller parameter $(C=22)$ compared to trend-line established for Super 718 .

closer lattice parameter match between the fcc $\gamma^{\prime}$ and the fcc $\gamma$ matrix results in greater thermodynamic stability of the precipitate phase and translates into reduced tendency towards precipitate coarsening and thus greater elevated temperature strength. The morphological change of the $\gamma^{\prime}$ particles would be strongly influenced by the lattice match between the $\gamma^{\prime}$ and $\gamma$ phases; therefore, the optimum heat treatment temperature would vary depending on lattice mismatch. For a modified alloy with a larger lattice mismatch, a lower temperature heat treatment would be desirable whereas for alloys with smaller mismatch a higher heat treatment temperature would be necessary. Also, a heat treatment for an appropriate composition that produces a partially compact or a complete compact $\gamma^{\prime} / \gamma^{\prime \prime}$ precipitate structure ${ }^{5}$ should be studied as the latter has shown attractive strength and thermal stability above $650^{\circ} \mathrm{C}$. With this in mind, the effects of various heat treatments on the mechanical properties of two modified 718 alloys from our initial study are reported.

\section{Materials and Procedure}

The two modifications of Alloy 718 employed in this study were produced as 5 $\mathrm{kg}$ or $23 \mathrm{~kg}$ ingots from VIM heats and given the initial processing previously described. ${ }^{1}$ Their chemical compositions taken from hot forged $32 \mathrm{~mm}$ bars are lisled in Table I. Appropriate specimens were cut from these bars and given the heat treatments listed in Table II, and several hardness measurements were made on the cross section of each specimen. I Iardness lests (Rc) were used as an economical indicator of mechanical strength and appropriate heat treatment for each alloy. Tensile and stress rupture tests followed standard procedures and were made at room temperature and at $700^{\circ} \mathrm{C}$ under $638 \mathrm{MPa}(92.5 \mathrm{ksi})$. For each heat treatment, thin foils were prepared and observed by transmission electron microscope. The $\gamma^{\prime}$ and $\gamma^{\prime \prime}$ phases were identified using electron diffraction and dark field techniques with (001) axis of the matrix parallel to the electron beam. 


\begin{tabular}{|c|c|c|c|c|c|c|c|c|c|c|c|c|}
\hline & & $\mathrm{Tab}$ & I & Chemic & $\operatorname{Comp}$ & sition of & Alloys & & & \multicolumn{3}{|c|}{ wt.\% } \\
\hline \multicolumn{2}{|c|}{ Alloy } & C & $\mathrm{Cr}$ & Mo & $\mathrm{Ti}$ & A! & & Sb & $\mathrm{Fe}$ & IV & B & \\
\hline \multirow{3}{*}{\multicolumn{2}{|c|}{$\begin{array}{l}3 \\
5\end{array}$}} & 0.056 & 17.58 & 2.85 & 0.97 & 0.86 & & 51 & 17.00 & .. & 0.00 & 33 \\
\hline & & 0.048 & 16.60 & 3.09 & 0.98 & 0.93 & & 57 & 13.71 & 2.30 & 0.00 & \\
\hline & & \multicolumn{2}{|c|}{ Table I. } & \multicolumn{5}{|c|}{ Chemical Composition of Alloys } & \multicolumn{4}{|c|}{ at. $\%$} \\
\hline Alloy & $\mathrm{Cr}$ & Mo & $\mathbf{T i}$ & A) & $\mathrm{Nb}$ & $\mathrm{Fe}$ & W & $\mathrm{Ni}$ & $\mathrm{Al}+\mathrm{T} \mathbf{i}$ & $\mathrm{Nh}$ & $\mathrm{Al} / \mathrm{T} \mathbf{i}$ & $\mathrm{Al}+\mathrm{Ti} / \mathrm{Nb}$ \\
\hline 3 & 19.60 & 1.72 & 1.18 & 1.85 & 3.44 & 17.65 & $-\cdot$ & 54.90 & 6.47 & & 1.57 & 0.88 \\
\hline 5 & 18.87 & 1.90 & 1.21 & 2.04 & 3.55 & 14.52 & 0.76 & 57.14 & 6.80 & & 1.69 & 0.92 \\
\hline
\end{tabular}

A number of heat treatments have been proposed to improve a specific property or to optimize a combination of properties. The grain size that develops as the result of solutioning the other microstructural variables, the $\delta$ morphology and the $\gamma^{\prime} / \gamma^{\prime \prime}$ precipitates are very important relative to ambient strength and rupture life at elevated temperatures. Our solutioning treatments of 1 hour at $980^{\circ} \mathrm{C}$ or $1030^{\circ} \mathrm{C}$ produced a grain size of ASTM6-7 and ASTM5-6 respectively and ASTM4-5 for the single $1050^{\circ} \mathrm{C}$ treatment. Koul et al ${ }^{6}$ have shown that grain coarsening occurs only above $1030^{\circ} \mathrm{C}$ when 1 hour treatments are employed, and this solution temperature was optimum for full solutioning of the above phases without inducing grain growth. Also, it should be noted that air cooling was employed after the solution anneals between $955^{\circ} \mathrm{C}$ and $1050^{\circ} \mathrm{C}$. Onyewuenyi ${ }^{7}$ has shown that there can be a variation in hardness with the rate of cooling from the annealing temperature but it is not significant above $980^{\circ} \mathrm{C}$ while at $955^{\circ} \mathrm{C}$ the hardness upon air cooling is equivalent to the value for a slow cooling in vermiculite. Finally, the selection of these temperature affects the age hardening response obtained by the selection of the double aging temperatures.

\section{$\underline{\text { Results }}$}

Employing the conventional solution treatment of $955^{\circ} \mathrm{C}$ for 1 hour and air cooling of the initial study, the effect of increasing the first stage aging temperature to 750,770 or $790^{\circ} \mathrm{C}$ for 8 hours and then air cooling was to maintain the hardness

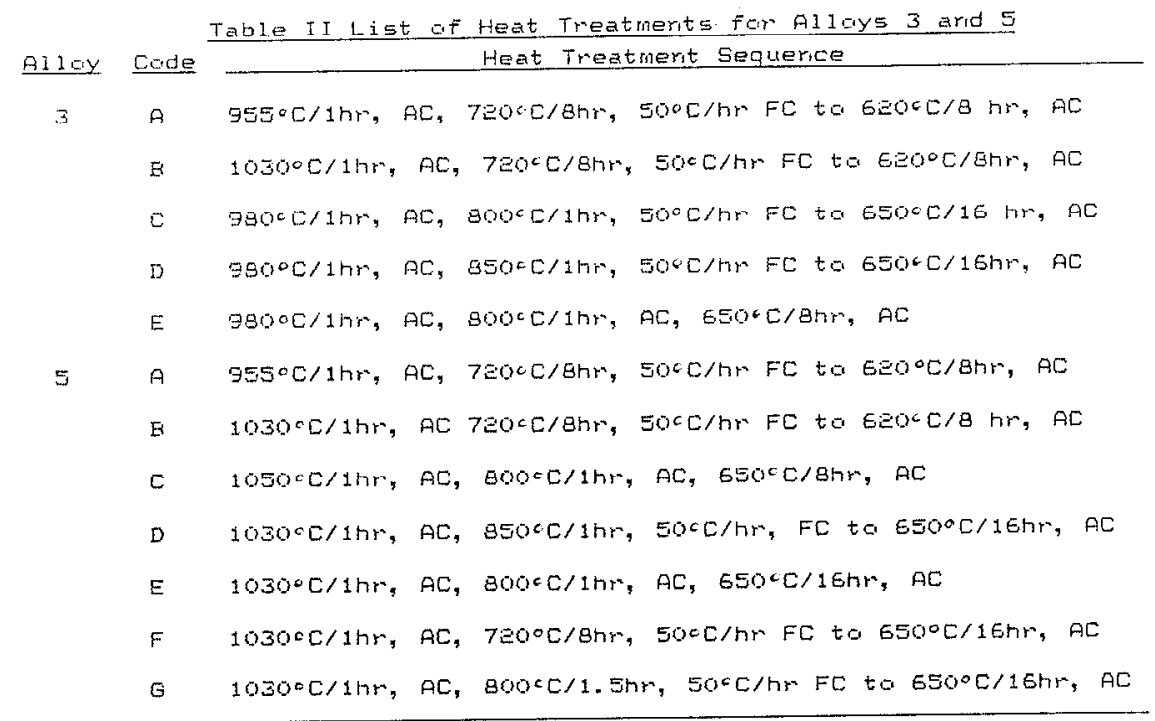

AC Signifies Air Cooled ard FC Sigrifies furruace CaGled 

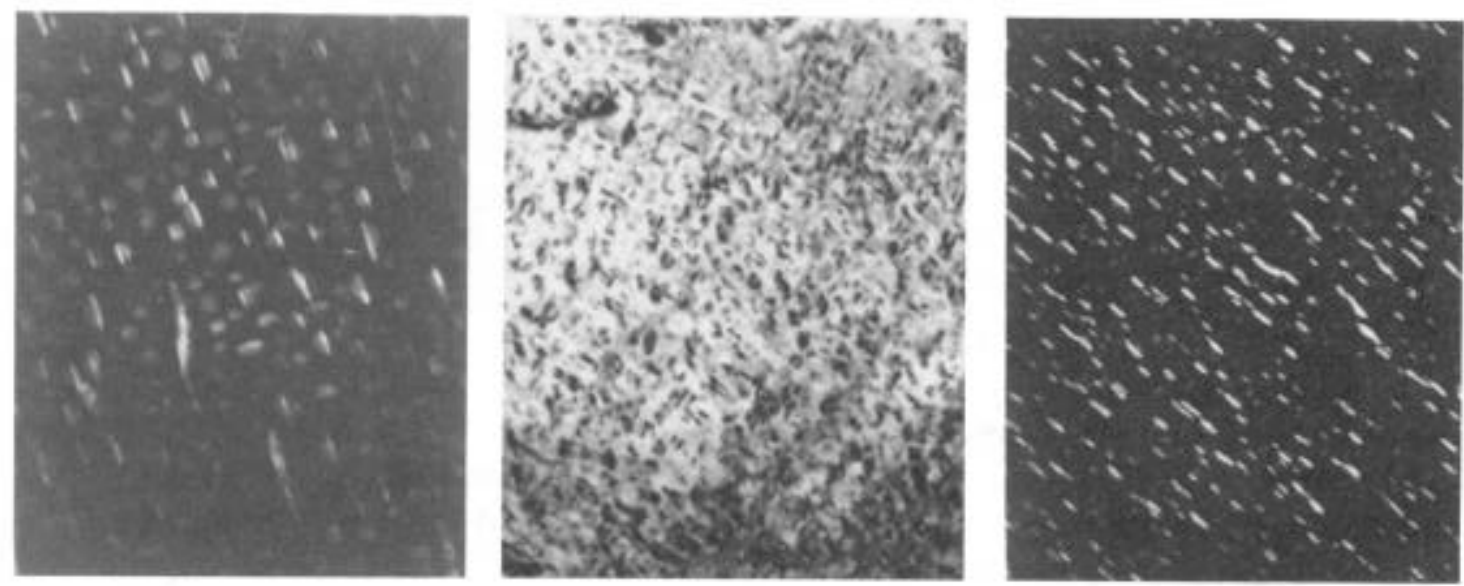

Figure 2. Transmission electronmicrographs on increasing primary aging temperature from 750 to $790^{\circ} \mathrm{C}$ after $955^{\circ} \mathrm{C}$ solution treatment. (a) Alloy $3,790^{\circ} \mathrm{C}$, dark field, X60000. (b) Alloy $5,750^{\circ} \mathrm{C}$, bright field, X60000. (c) Alloy $5,790^{\circ} \mathrm{C}$, dark field, X37000.

of alloy 3 at Rc40 between 750 and $770^{\circ} \mathrm{C}$. It then decreased to Rc36.5 after aging at $790^{\circ} \mathrm{C}$. The hardness of Alloy 5 decreased in a straight-line from Rc40 to Rc39 to $\mathrm{Rc} 38$ for the three temperatures. As seen in Figure 2 raising the primary aging temperature from $750^{\circ} \mathrm{C}$ to $790^{\circ} \mathrm{C}$ still produced the conventional non-compact precipitate structure and these results led to the consideration of even higher first stage aging treatments coupled with higher solution temperatures.

In the case of Alloy 3, a solution temperature of $980^{\circ} \mathrm{C}$, coupled with an increasing first stage aging temperature between 750 and $850^{\circ} \mathrm{C}$, and then secondary aging at $650^{\circ} \mathrm{C}$ for 8 hours, produced a rising hardness from Rc45.5 to almost Rc48, per Figure 3. Increasing the solution temperature to $1010^{\circ}$ or $1030^{\circ} \mathrm{C}$ did not achieve these hardness values. The next best Rc46 hardness was obtained with a $1030^{\circ} \mathrm{C}$ solution treatment and $800^{\circ} \mathrm{C}$ first stage aging treatment, while a solution treatment at $1010^{\circ} \mathrm{C}$ and $850^{\circ} \mathrm{C}$ first stage aging treatment reached about Rc45.5. The use of a lower second stage aging at $620^{\circ} \mathrm{C}$ produced inferior hardness in both cases. Also, it should be noted that a hardness of Rc41 to 42.5 was obtained when a lower first stage age at $750^{\circ} \mathrm{C}$ was used in these treatments, compared to Rc45.5 for the $980^{\circ} \mathrm{C}$ solution temperature. Transmission electron micrographs, Figure 4, revealed that a partial compact $\gamma^{\prime} / \gamma^{\prime \prime}$ precipitate structure was obtained with heat

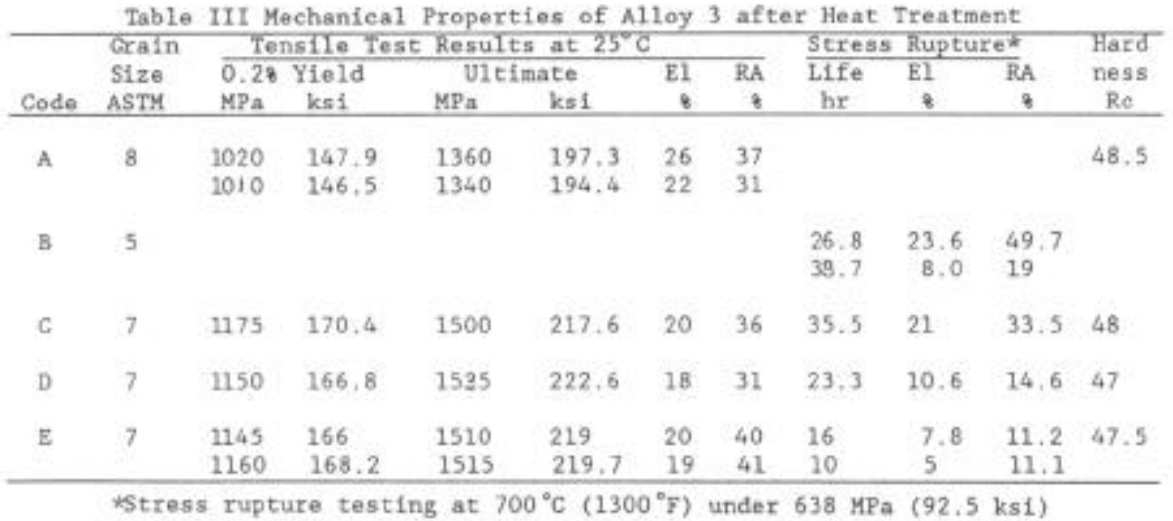



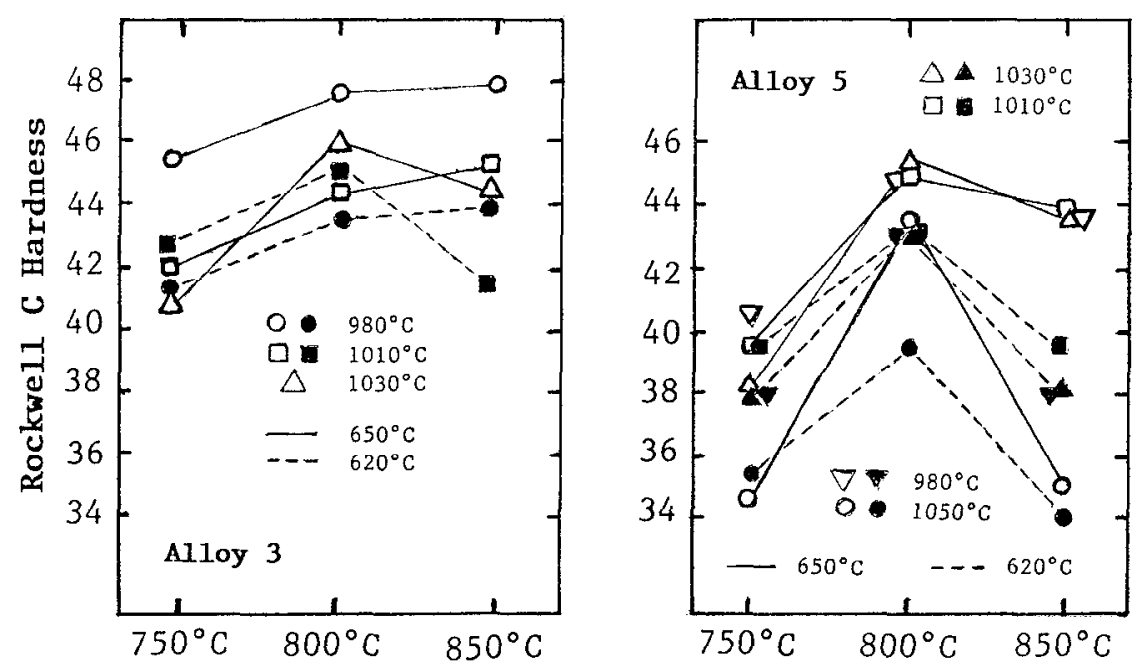

Figure 3 - Hardness variations in Alloy 3 and 5 after the heat treatments listed in Table II.

treatment $C$ and a compact $\gamma^{\prime} / \gamma^{\prime \prime}$ precipitate structure was obtained with heat treatment $\mathrm{D}$.

Mechanical properties for Alloy 3 employing the specified heat treatments are presented in Table III. In room temperature tensile tests, higher yield and ultimate strength were obtained with the optimum being a trade-off between heat treatments $C$ and $D$. Hence, one would conclude that the difference between the partially compact and the compact $\gamma^{\prime} / \gamma^{\prime \prime}$ precipitate structure produced by these heat treatments, per Figure 4, provided no difference in room temperature strength of Alloy 3. On the other hand, stress rupture life at $70^{\circ} \mathrm{C}$ under $638 \mathrm{MPa}$ (92.5 ksi) was significantly longer at 35.5 hours for the former compared to 23.3 hours for the latter which is somewhat surprising. This will be verified by additional testing in the sequel study. Also, it should be noted that the stress rupture results for these heat treatments are equivalent to those obtained for heat treatment $\mathrm{B}$ utilizing a higher $\left(1030^{\circ} \mathrm{C}\right)$ solution treatment and lower first stage aging temperature. The coarser grain size of heat treatment B (ASTM5 vs 7) would be expected to improve rupture life.

As seen in Figure 3, increasing the solution temperature between $980^{\circ} \mathrm{C}$ and $1030^{\circ} \mathrm{C}$ in Alloy 5 , coupled with a primary aging at $800^{\circ} \mathrm{C}$ and secondary aging at $650^{\circ} \mathrm{C}$, produced a maximum hardness of Rc45 and it dropped gradually to Rc 43.5 when the primary aging temperature was raised to $850^{\circ} \mathrm{C}$. Increasing the solution temperature to $1050^{\circ} \mathrm{C}$ produced a wide variation with a maximum Rc 43.5 at $800^{\circ} \mathrm{C}$ while the use of a lower secondary aging at $620^{\circ} \mathrm{C}$ produced a similar variation with inferior hardness compared to the values obtained with the $650^{\circ} \mathrm{C}$ treatment. Transmission electron micrographs, presented as Figure 5, revealed that coarser $\gamma^{\prime \prime}$ particles were obtained for the $1030^{\circ} \mathrm{C}$ and $850^{\circ} \mathrm{C}$ aging treatment $\mathrm{D}$ compared to the lower $800^{\circ} \mathrm{C}$ aging treatment $\mathrm{G}$ which produced smaller, closely spaced $\gamma^{\prime \prime}$ particles with smaller, barely resolvable $\gamma^{\prime}$ particles. These results led to the selection of either a $1030^{\circ} \mathrm{C}$ or $1050^{\circ} \mathrm{C}$ solution treatment coupled with an $800^{\circ} \mathrm{C}$ or $850^{\circ} \mathrm{C}$ first stage aging (heat treatments $\mathrm{D}$ and $\mathrm{G}$ ) for the determination of mechanical properties. 

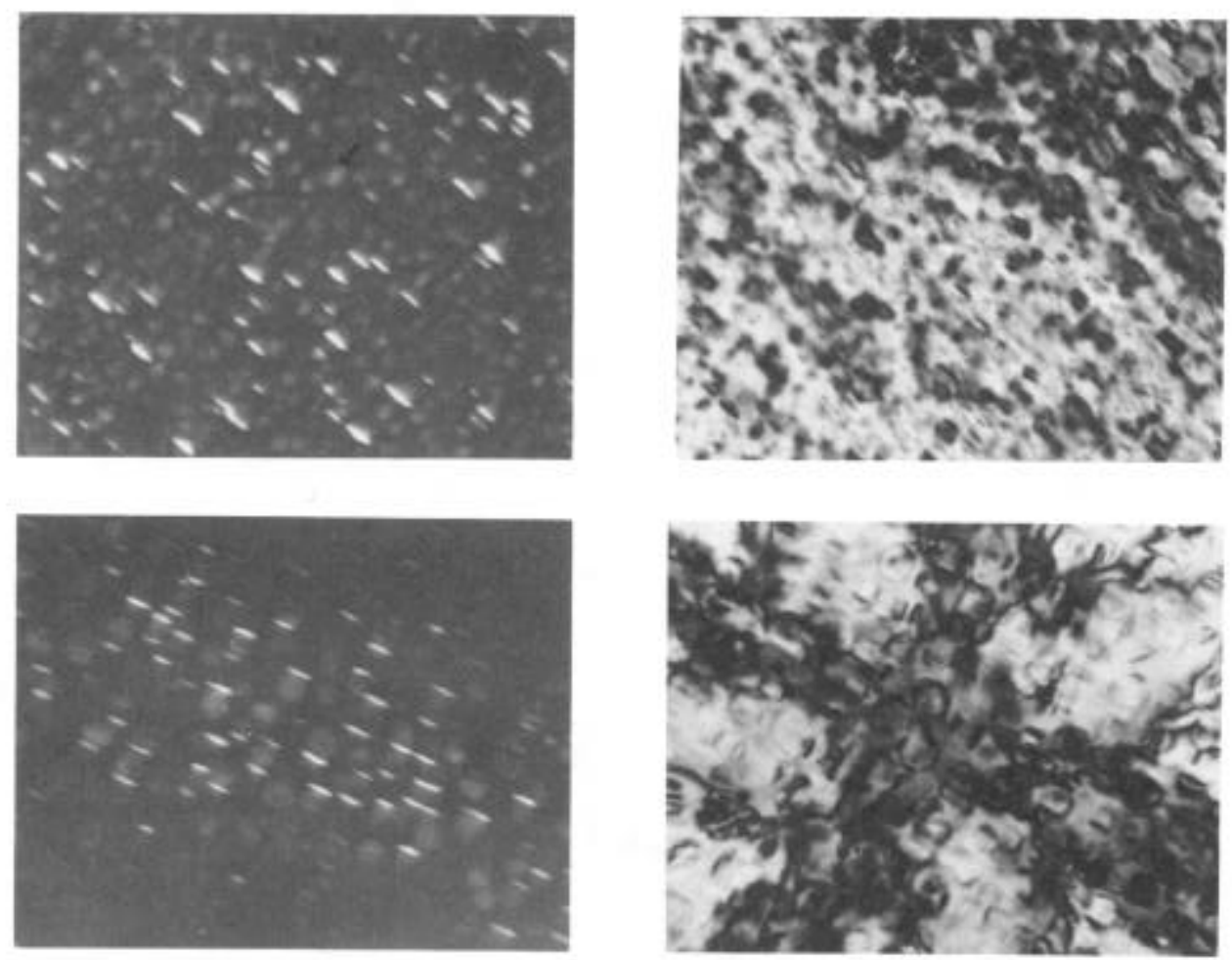

Figure 4. Transmission electronmicrographs of Alloy 3. (a,b) Partial compact $\boldsymbol{\gamma}^{\prime}-\boldsymbol{\gamma}^{\prime \prime}$ precipitates after heat treatment C. (c,d) Compact $\boldsymbol{\gamma}^{\prime}-\boldsymbol{\gamma}^{\prime \prime}$ precipitates after heat treatment D. Dark and bright field X80000.

In Table IV, the mechanical properties of Alloy 5 employing heat treatments C to $G$ are compared with these obtained previously with the standard 718 heat treatment. Both higher yield and ultimate strength in tensile tests at room temperature were obtained with the new heat treatments, with the highest values evident for $\mathrm{D}$ and $\mathrm{G}$ employing the $1030^{\circ} \mathrm{C}$ solution treatment with primary aging at $800^{\circ} \mathrm{C}$ or $850^{\circ} \mathrm{C}$ and longer secondary aging at $650^{\circ} \mathrm{C}$. It is noteworthy that the values obtained for a coarser ASTM5 -6 are even higher than those obtained with a
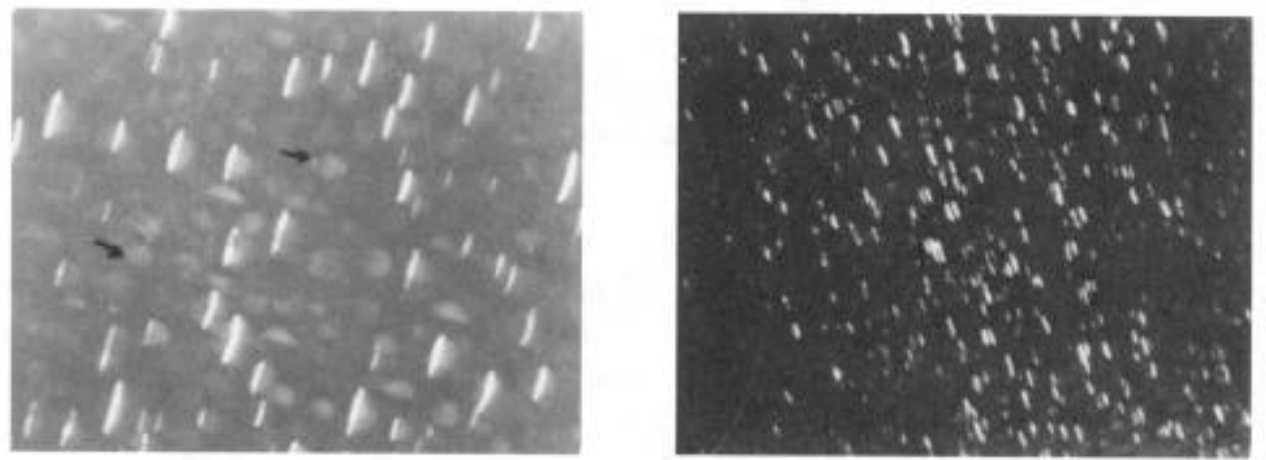

Figure 5. Transmission electronmicrographs of Alloy 5.

(a) Partial compact $\boldsymbol{\gamma}^{\prime}-\boldsymbol{\gamma}^{\prime \prime}$ precipitates after treatment D and (b) after treatment $G$. Dark field, $X 80000$. 


\begin{tabular}{|c|c|c|c|c|c|c|c|c|c|c|c|}
\hline \multirow[b]{3}{*}{ Code } & \multirow{3}{*}{$\begin{array}{l}\text { Graín } \\
\text { Size } \\
\text { ASTM }\end{array}$} & \multirow{2}{*}{\multicolumn{4}{|c|}{$0 . \frac{\text { Tensile Test Results at } 250}{28 \text { Yield }}$}} & \multirow{3}{*}{$\begin{array}{r}\text { EI } \\
8 \\
\end{array}$} & \multirow{3}{*}{$\begin{array}{r}\mathrm{RA} \\
8 \\
\end{array}$} & \multicolumn{3}{|c|}{ Stress Rupture* } & \multirow{3}{*}{$\begin{array}{c}\text { Hard- } \\
\text { ness } \\
\text { Ro }\end{array}$} \\
\hline & & & & & & & & Life & $\mathrm{EI}$ & $\overline{R A}$ & \\
\hline & & $\mathrm{MPa}$ & ksi & $\mathrm{MPa}$ & ksi & & & hr & 8 & 8 & \\
\hline \multirow[t]{2}{*}{ A } & $8-9$ & 950 & 137.8 & 1310 & 190 & $\because 5$ & $9^{7}$ & & & & \multirow[t]{2}{*}{46} \\
\hline & & 970 & 143.6 & 1330 & 192.9 & 29 & 46 & & & & \\
\hline$B$ & $5-6$ & & & & & & & 40.1 & 13.6 & 50.2 & \\
\hline \multirow[t]{2}{*}{ C } & $4-5$ & 1030 & 149.4 & 1370 & 198.7 & 24 & 49 & 36.8 & 5.3 & 7.1 & \multirow[t]{2}{*}{43.5} \\
\hline & & 1070 & 155.2 & 1385 & 200.9 & $2 / 4$ & 199 & 28.3 & 5.1 & 11.8 & \\
\hline D & $5-6$ & 1075 & 155.9 & 1455 & 211.0 & 21 & 35 & 31.7 & 4.5 & 7.5 & \\
\hline E & $5-6$ & 1090 & 158.1 & 1395 & 202.3 & 26 & 42 & 32.8 & 4.3 & 6.9 & 45.4 \\
\hline F & $5-6$ & 930 & 134.9 & 1350 & 195.8 & 31 & 46 & 21.3 & 9.7 & 18.6 & \\
\hline G & $5-6$ & 1110 & 161.0 & 1485 & 215.4 & 22 & 37 & 30.4 & 6.4 & 11.2 & \\
\hline
\end{tabular}

finer ASTM8-9 grain size obtained via the lower $955^{\circ} \mathrm{C}$ soluticn temperature of treatment $\mathrm{A}$. On the other hand, on an equivalent grain size basis, the stress rupture life values for the new heat treatments are somewhat lower than originally. In our sequel study, more data will be obtained to establish average values for heat treatment $G$ which has been selected at the best way to produce a fine non compact $\gamma^{\prime} / \gamma^{\prime \prime}$ precipitate structure in Alloy 5 .

- Alloy 3 and Alloy 5 have essentially the same base composition except for an addition of tungsten to provide a solid solution strengthening effect in Alloy 5. Ambient tensile yield and ultimate strength of both was improved in all heat treatments when compared with the standard 718 heat treatment. The result obtained with the lower solution temperature for Alloy $3\left(980^{\circ} \mathrm{C}\right.$, finer ASTM7 grain size) produced slightly higher values than those obtained with the higher solution temperature on Alloy $5\left(1030^{\circ} \mathrm{C}\right.$, ASTM5-6 grain size), except that heat treatment $G$ for Alloy 5 provided equivalent values. Also, this heat treatment and grain size provided an improvement in the time to rupture at $700^{\circ} \mathrm{C}$ and $638 \mathrm{MPa}$. Heat treatment $G$ for Alloy 5 was selected on the premise that a longer primary aging time may improve grain boundary plasticity to elevate stress rupture and elongation and a longer secondary aging time may elevate strength.

\section{References}

1. E. Gou, F. Xu and E.A. Loria, Superalloy 718: Metallurgy and Applications, TMS (1989), pp. 567-576.

2. J.P. Collier, S.H. Wong, J.C. Phillips and J.K. Tien, Metall. Trans., 19A (1988), pp. 1657-1666.

3. J.P. Collier, A.O. Selius and J.K. Tien, Superalloys 88, TMS (1988), pp. 43-52.

4. R. Cozar and A. Pineau, Metall. Trans., 4 (1973), pp. 47-59. 
5. E. Andrieu, R. Cozar and A. Pineau, Superalloy 718: Metallurgy and Applications, TMS (1989), pp. 241-256.

6. A.K. Koul, P. Au, N. Ballinger, R. Thamburaj, W. Wallace and J.P. Immerigeon, Superalloys 88 , TMS (1988), pp. 3-12.

7. O.A. Onyewuenyi, Superalloy 718: Metallurgy and Applications, TMS (1989), pp. 345-362. 